\title{
Opening the black box on bank efficiency in China: does economic freedom matter?
}

\begin{abstract}
The paper provides, for the first time, empirical evidence on the impact of economic freedom on bank efficiency in a developing economy. We employ the Data Envelopment Analysis method to compute the efficiency of the Chinese banking sector during 2000-2008. The empirical findings indicate that the inefficiency of the Chinese banking sector stems largely from scale rather than pure technical. By examining different dimensions of economic freedom, we find that not all are equally regressive on bank efficiency. We find that the impact of business freedom to be positive, implying that higher (lower) freedom for entrepreneurs to start businesses increases (reduces) bank efficiency. Similarly, monetary freedom is positively related to bank efficiency levels, indicating the importance of a stable and reliable monetary policy to business environment. On the other hand, the impact of financial freedom is negative, implying that higher (lower) financial freedom reduces (increases) the efficiency of banks operating in the Chinese banking sector.
\end{abstract}

Keyword: Economic freedom; Bank efficiency; Data envelopment analysis; Panel regression analysis; China 